\title{
Cloud Data Transfer and Secure Data Storage
}

\author{
Md Haris Uddin Sharif, Ripon Datta
}

\begin{abstract}
Using shippable devices which means the utilization of physical shippable gadgets when you need to do disconnected one-time data transfers. If company send disk or a protected specific tool. Besides that, we can buy and ship your very own disks. Your duplicate information to the gadget and afterward deliver it to Azure where the information is uploaded. The accessible choices for this case are Data Box Disk, Data Box, Data Box Heavy, and Import/Export (utilize your disks) [1]. In this Paper we will focus Cloud computing risk, ship cloud data, storage and best practice of incident management.
\end{abstract}

Index Terms - Cloud Data Storage Service, Cloud Computing Security, Cloud Computing Risk, Best Practice for Incidence Management.

\section{INTRODUCTION}

You do the transferring of your data to Azure through the connection of your network. There are many ways of doing it. One of them is Graphical interface-If you once in a while transfer only a couple of documents and don't have to automate the data movement, you can pick a graphical interface instrument, for example, Azure Storage Explorer or a web-based exploration device in Azure portal. [1]. Programmatic transfer or Scripted - In this, it is advisable to use software tools that are optimized that are provided or known as our SDKs/ REST APIs directly. The found scriptable devices are Azure CLI, Azure PowerShell, and AzCopy. For programmatic interface, use one of the SDKs for. Python, NET, Java, Node/JS, C++, Go, Ruby or PHP [1]. On-premise devices -We supply you a physical or virtual gadget that lives in your datacenter and upgrades data transfer over the system of the network. These devices likewise give a local cache of habitually utilized records. The physical gadget is the virtual gadget is the Data Box Gateway and the Data Box Edge. Both run forever on your premises and interface with Azure over the system [1]. Managed data pipeline -You can set up a cloud pipeline to routinely move documents between a few Azure administrations, on-premises or a joining of the two. Utilize Azure Data Factory to set up and oversee information pipelines, and move and change information for analysis [1].

\section{LITERATURE REVIEW}

The trend of the enormous computerized information era is influencing each business.

As indicated by analyst reports, the interest for data storage across the world hit to about 15,000 exabytes a year ago. With such an amazing figure, it is clear why preferring an expert

Md Haris Uddin Sharif, Department of Information Technology, University of the Cumberlands, Kentucky, United States of America.

Ripon Datta, Department of Information Technology, University of the Cumberlands, Kentucky, United States of America. storage arrangement is a common challenge in the business world. If you are uncertain, you can evaluate the measure of capacity you have now and contrast it with your needs in five years. Indeed, you can limit the size of your worker's inboxes and the measure of capacity they can use on the organization shared drive. Notwithstanding, to what extent will your business have the option to continue these limitations? You will arrive at a point where your business exceeds your information storage. You ought to have just addressed the issue of why you are buying storage by this point. Ordinarily, the objective is to bring down IT costs, improve profitability, or bolster business development. Rather than purchasing physical servers or include hard drives that you need to keep up, you can unify your information storage and the board in the cloud. Information security is a crucial issue to address when picking and executing a capacity arrangement. Without a sound storage security technique set up, you risk losing your touchy information. With the recurrence of information breaches turning out to be increasingly disturbing, you ought to coordinate security arrangements into each progression of your information the management process. Another factor to think about when choosing a professional information storage arrangement is deduplication. This is the way toward distinguishing one of a kind information segments by contrasting them and recently stored information. With an autonomous reinforcement, similar information can persistently be saved after deduplication is finished. Why save and reinforcement copy information in any case? The deduplication procedure saves just the special information in a compacted arrangement. When you have selected the storage choice, you can decide the performance and limit of your choice. The limit is anything but difficult to decide and the most evident capacity. Execution can be anything but difficult to disclose yet difficult to measure. You may experience considerable difficulties deciding the required data transmission, idleness, and burst speeds. In the other way, that considering moving to or purchasing extra shared storage in the cloud, think about the unwavering quality behind it. You have to pick a tenable seller or a data server supplier and guarantee the S.L.A is custom-made to your needs. [2]

Cloud security is also known as Cloud computing security which is defined as wide policies that are set, new technologies, usability, including management utilized so that to secure virtualization of the IP, message, usability, authorities, including associated foundations with distributions of the computing.

\section{Cloud COMPuting SECURITY ISSUES}

Security of data - It's nothing unexpected that information security bests the rankings of concerns that keep organizations away from cloud adoption. $73 \%$ of study respondents demonstrated this is a major warning for them. Cloud provider 
organizations are targets of information breaches (for example email services SendGrid and online note-taking help Evernote), which makes it basic for organizations to utilize risk relief procedures and strategies, for example, tokenizing or encrypting information before it ever goes to a cloud service [3].

Non-compliance having regulatory mandates - GLBA, FISMA, FERPA, PCI DSS, HIPAA/HITECH, EU data protection, et. al. Whatever the administrative abbreviation, you will locate that $38 \%$ of organizations are worried about how they can guarantee consistency with guidelines if their information is in the cloud. A security breach that prompts rebelliousness with an administrative mandate can bring about costly fines, loss of business, claims, and conceivably even criminal punishments (as on account of ITAR non-compliance) [3].

Losses of the controls over IT service $-38 \%$ of the CSA review respondents state their dread over the loss of control shields them from moving information into cloud-based applications. This loss of control can be shown from multiple points of view. The cloud provider may pick how and where information is stored; how regularly it is backed up; which encryption plan is utilized, on the off chance that one is utilized by any means; which of its workers have physical or virtual access to the information; and much. In any case, considering if cloud providers organization invoke sentiments of complete trust, the reality remains that the information proprietor is as yet obligated for any information breach that may happen, and this leaves more than $1 / 3$ of all organizations reluctant to utilize cloud services [3].

The expertise of IT and business managers $-34 \%$ of organizations aren't getting on board with the cloud temporary fad since they accept the information and experience of their IT and business managers are not lined up with the ranges of abilities that distributed computing requests. For instance, notwithstanding the specialized learning a manager is relied upon to have, the individual additionally needs money related proficiency for another processing model where administrations are leased, not claimed, in addition to exchange aptitudes to drive a cloud supplier's SLA to the organization's advantage [3].

Insider dangers or compromised accounts $-30 \%$ of the CSA review respondents are worried about what might occur if their records held by a SaaS supplier were to be undermined somehow or another, or if an insider with that supplier did a little "extra-curricular action" and jabbed around in private records. Their worries are not lost. Out of this world's very own investigation has discovered that $92 \%$ of organizations have employees with traded off qualifications for deals on the darknet. What's more, the occurrence of insider risks is a lot higher than generally known by the IT department [3].

Businesses continuity and disaster recovery - What befalls an organization on the off chance that it loses all access to its IT infrastructure its cloud supplier has all of a sudden left business? It's an uncommon situation, thank goodness, however, it occurs, and this makes $28 \%$ of the CSA study respondents excessively apprehensive to embrace distributed computing. An organization doesn't surrender its commitment to do appropriate business congruity and disaster recovery arranging since it never again works the physical parts of its IT framework, however, recovering information from outdated cloud services and finding an elective home for that information can be an enormous challenge [3]. CloudWatch provides secure user and resources monitoring while WAF acts as firewall protecting application from external attacks [9]. In the data environment, every business needs to put considerable focus on securing, creating a conducive infrastructure, and ensuring that information is efficiently and accurately governed [12].

\section{FACTS ABOUT ClOUd COMPUTING SECURITY}

All organizations are defenseless against cyber attacks. Regardless of size (and the numbers state independent business are the greatest focuses for cyber attacks), every business ought to arm itself against hackers, malware and viruses. This security ought to be left to the experts, as any mistake could be welcoming attackers. Distributed computing is a basic factor here - it's fundamental for recovery. If your information isn't backed up locally and in the cloud, you could have a significant issue recovering your information and your business ready for action [4]. Talking about local backups, an information server situated in your office is basic in numerous organizations. While we don't recommend disposing of your more up current server altogether, studies have demonstrated that $80 \%$ of organizations bought a server with more capacity than they required. This is a costly piece of equipment that necessities replacement at regular intervals of 5 years averagely. It's not important to pay for a whole server when you just utilize $20 \%$ of it. This is the place in which cloud computing is featured on. The cloud is compensation as you develop a solution. Since your information is stored in a gigantic distribution center loaded with servers, you pay for the definite measure of capacity your information requires [4]. The cloud is all over. A cloud-based innovation called a website with several things is turning into a basic part of daily life. Gadgets like smart home security frameworks, Alexa and Siri are just the starts. As the IoT forms into progressively complex frameworks, they'll be utilizing increasingly more of the cloud. (Fortunately, the cloud is practically limitless). It's proposed a rise to 20 billion IoT gadgets by 2020 [4].

Regardless of whether you don't bother with your information in the cloud to work your business, producers, for example, it's impossible that your office staff feel a similar route as your distribution center group. Over $90 \%$ of offers and advertising groups need cloud-based applications to complete their employments. Applications like Infusion soft, sales force and even your site and web-based life are all cloud-based innovations. [4] A surprising measure of information is being stored in the cloud. It's evaluated at 1.1ZB (that is zettabyte, which equivalents a trillion GB. Your mobile phone likely has $16 \mathrm{~GB}$ or $32 \mathrm{~GB}$ stockpiling limit). This cloud information is twice what it was a year ago, and it's just going to increase. 
Fortunately, we have the innovation and the space to get that going [4].

\section{RISKS WITH CLOUD COMPUTING}

Companies successfully keep sensitive data at the clouds. An analysis done discovered $21 \%$ of records kept to cloud's document-sharing services contain delicate information such as intellectual innovation. At the point when a cloud service is broken, cyber hackers can access this delicate information. Missing a breach, certain services can even represent a risk if their terms and conditions guarantee responsibility for information transferred to them [5].

Nowadays, most organizations work under a type of administrative control of their data, regardless of whether it's HIPAA for private health data, FERPA for secret learners' records, or one of numerous other government and industry guidelines. Under these principles, organizations must know where their information is, who can get to it, and how it is being ensured. BYOC frequently disregards all of these fundamentals, placing the organization in a condition of rebelliousness, which can have unexpected repercussions [5].

At the point when organizations are uninformed about staff utilizing cloud benefits, those workers can be doing pretty much anything and nobody would know until it's past the point of no return. For example, a sales representative who is going to leave the organization could download a report of all client contacts, transfer the information to an individual distributed storage service, and afterward get to that data once she is utilized by a contender. The first model is one of the more typical insider risks today [5].

Cloud services can be utilized in vector form for information exfiltration. Out of this, Skyhigh revealed a novel information exfiltration system whereby hackers encoded delicate information into video documents and transferred them to YouTube. We've additionally distinguished malware that exfiltrates delicate information through a private Twitter account 140 characters one after another. On account of the Dyre malware variation, digital hoodlums utilized record sharing services to convey the malware to targets utilizing phishing assaults [5].

Agreements among business parties frequently limit how information is utilized and who is allowed to get to it. At the point when workers move confined information into the cloud without approval, the business agreements might be disregarded and lawful activity could result. Consider the case of cloud services that keeps up the privilege to share all information transferred to the service with outsiders in its terms and conditions, in this manner breaching privacy understanding the organization made with a colleague [5].

Information breaches unavoidably bring about reduced trust by clients. In amongst the huge breaches of installment card information ever, cyber hackers took more than 40 million client credit and charge card numbers from Target. The breach drove clients to avoid Target stores and prompted lost business for the organization, which eventually affected the organization's income. See number 9 beneath [5].

On the off chance that touchy or directed information is placed in the cloud and a breach happens, the organization might be required to unveil the breach and send notices to potential unfortunate casualties. Certain guidelines, for example, HIPAA and HITECH in the healthcare industry require these discloses. Following lawfully ordered breach discloses, controllers can impose fines against an organization and it's normal for buyers whose information was undermined to document claims [5].

If clients even presume that their information isn't completely ensured by big business enterprise security controls, they may take their business somewhere else to an organization they can trust. A developing chorale of pundits is training purchasers to stay away from cloud organizations who don't secure client privacy [5]

Updates on the Target information breach stood out as truly newsworthy and numerous purchasers avoided Target stores over the bustling Christmas season, prompting a $46 \%$ drop in the organization's quarterly benefit. The organization evaluated the breach extreme expense of $\$ 148$ million. Subsequently, the CIO and CEO surrendered and many are currently calling for expanded oversight by the top managerial staff over digital security programs [5].

\section{MANAGEMENT INTERFACE VULNERABILITY}

With regards to architecture structure, one region that is frequently not given due thought is the security of the administration interfaces utilized by managers or administrators to arrange their foundation. These are the interfaces used to perform special activities on frameworks, and all things considered they're a significant prize for an attacker who needs to oversee your framework. There is a large category of board interfaces for various advances. These incorporate progressively conventional administration interfaces, (for example, consoles and remote work areas), program based administrator interfaces to arrange foundation, and online interfaces to design many cloud services [6].

\section{BEST PRACTICE FOR SECURITY INCIDENTS MANAGEMENT}

Security occurrence the executives is a basic control by ISO 27001 models (Clause A13) and has an equivalent, if not higher, level of significance in different principles and systems. Occurrence the executives frame a basic piece of an association's security approaches and systems identifying with reinforcement, congruity, debacle recuperation (DR), chance administration, and arrangement the board. At the national level, the Computer Emergency Response Team (CERT) reacts to and oversees security episodes, proactively giving warnings and keeping a watch on the general risk situation.

Characterized jobs and duties regarding the occurrence response group, which will have useful (improvement, infrastructure) just as business (deals, organization, legitimate, money) administrators. RACI diagram that recognizes the individual who is Responsible, Accountable, Consulted or 
Informed for characterized exercises when an occurrence. Preparing a program for all exercises characterized inside the security episode the board work on, including utilitarian, operational and strategic abilities. Occasional preparing utilizing test situations and practical preparing must be given routinely. Agendas and formats for operational upkeep reaction dependent on arrangement things, including techniques for shutdown, startup, rebuilding, and others. Characterize joins/contact focuses/conditions of the security episode the executive's approach and strategies with other data security the board framework controls. For example, RACI graphs, the board contact data, agendas, startup and shutdown methods would be normal to security occurrence the board and DR. Other contact focuses would be chance the executives since the effect 'high' dangers might be tended to through proactive relief measures in the security occurrence the board forms. Proof gathering strategies to guarantee it is 'great', forensically and legitimately stable, as a component of first security occurrence the board reaction. This is a specific capacity, and an association stands to lose a great deal if the proof is erroneous or deficient. Acknowledgment in the official courtroom or fittingness for investigation can be influenced in the event of an imperfect proof accumulation process. There are millions of smart phones which are stolen every year [11].

Utilitarian and legal science procedure for isolating and regulation, continuous perception, examination, investigation, and announcing. This is an assistant to the proof gathering procedure, and colleagues having the necessary aptitudes ought to be deputed to complete this duty. The consciousness of obligation regarding organization, legitimate, HR, and fund groups. It is vital for all capacities in an association to be sharpened to one another's duties and liabilities during an occurrence. Gaining from the episode and refreshing powerlessness/risk store and other such measures to guarantee proactive controls. All business and useful directors must take an interest in the investigation and learning sessions and guarantee that the security episode the board procedures and documentation are refreshed. Measurements and important answering to the executives and different partners ought to identify with useful and monetary issues. For example, a report can give measurements to recuperation happening sooner than the administration level understanding, bringing about investment funds in cost and profitability [7]

\section{PROPOSED WAYS TO MOVE DATA TO CLOUD ENVIRONMENTS AND STORAGES}

One arrangement offered by cloud sites is the alternative of acquiring committed availability from the client's data center to one of the supplier's worldwide connection areas. Amazon's AWS Direct Connect and Microsoft's Azure Express Route give the interconnect guide fundamental toward associate utilizing autonomously provisioned committed circuits and IP-layer connection. Such arrangements guarantee to give more noteworthy security, greater unwavering quality, lower inertness, and higher speeds than moving records over the open Internet and can be a convincing and financially savvy answer for specific circumstances. Another method face transferring enormous records to protest stockpiling is to utilize a utility that will 'chunk' or 'cut' huge documents into numerous parts, send the different parts in parallel, and afterward reassemble them at the cloud place. By and by, clients think that it is hard to assemble powerful arrangements with this utility that work dependably under the heap of huge informational collections being moved over the open Internet. For arrangements at scale, a straightforward multi-part transfer execution is probably not going to give adequate speed and dependability, and designing speculation will be required to work out a versatile usage. Both AWS and Azure offer one more way to deal with a similar test through their individual AWS Import/Export Disk and Azure Import/Export services. Here the information is moved between the client's on-premises storage and distributed storage using physical hard drives transported between the client and the cloud supplier. Different types of UDP accelerating innovations are accessible available. Both industrially and Open Source Commercial on-premises UDP software can be conveyed on VMs in the cloud, however, this doesn't create a hearty outcome and requires noteworthy forthright and continuous resource investment. [8]. In late 2017, Amazon declared new voice-enacted instruments for the working environment, trusting that verbal directions, for example, "Alexia [10] might store data on AWS cloud therefore all smart device would get best scope to store data and use cloud data.

\section{REFERENCES}

[1] G. O. Young, "Synthetic structure of industrial plastics (Book style with paper title and editor)," in Plastics, 2nd ed. vol. 3, J. Peters, Ed. New York: McGraw-Hill, 1964, pp. 15-64.

[2] W.-K. Chen, Linear Networks and Systems (Book style). Belmont, CA: Wadsworth, 1993, pp. 123-135.

[3] H. Poor, An Introduction to Signal Detection and Estimation. New York: Springer-Verlag, 1985, ch. 4.

[4] B. Smith, "An approach to graphs of linear forms (Unpublished work style)," unpublished.

[5] E. H. Miller, "A note on reflector arrays (Periodical style-Accepted for publication)," IEEE Trans. Antennas Propagat., to be published.

[6] J. Wang, "Fundamentals of erbium-doped fiber amplifiers arrays (Periodical style-Submitted for publication)," IEEE J. Quantum Electron., submitted for publication.

[7] C. J. Kaufman, Rocky Mountain Research Lab., Boulder, CO, private communication, May 1995.

[8] Y. Yorozu, M. Hirano, K. Oka, and Y. Tagawa, "Electron spectroscopy studies on magneto-optical media and plastic substrate interfaces (Translation Journals style)," IEEE Transl. J. Magn.Jpn., vol. 2, Aug. 1987, pp. 740-741 [Dig. $9^{\text {th }}$ Annu. Conf. Magnetics Japan, 1982, p. 301].

[9] Sharif MHU, Datta R(2019). SOFTWARE AS A SERVICE HAS STRONG CLOUD SECURITY. Retrieved from URL: https://www.researchgate.net/profile/Haris_Sharif/publication/335232 826_Software_as_a_Service_has_Strong_Cloud_Security/links/5d646 6fc299bf1f70b0eb0f2/Software-as-a-Service-has-Strong-Cloud-Securit y.pdf

[10] Sharif MHU, Datta R,. Valavala M.(2019). Biometrics Authentication Analysis. International Journal of Mathematics Trends and Technology (IJMTT) - Volume 65 Issue 10 - Oct 2019 http://www.ijmttjournal.org/Volume-65/Issue-10/IJMTT-V65I10P506. pdf

[11] Sharif MHU, Datta R, (2019).BRING YOUR OWN DEVICE (BYOD) PROGRAM. International Journal of Engineering Applied Sciences and Technology, 2019 Vol. 4, Issue 4, ISSN No. 2455-2143, Pages 36-40.DOI: www.ijeast.com/papers/36-40,Tesma404,IJEAST.pdf

[12] Sharif MHU, Datta R, (2019). Information Governance: A Necessity in Today's Business Environment. IJCSMC, Vol. 8, Issue. 8, August 2019,pg.67-76.From 
https://www.academia.edu/40224559/Information_Governance_A_Ne cessity_in_Todays_Business_Environment

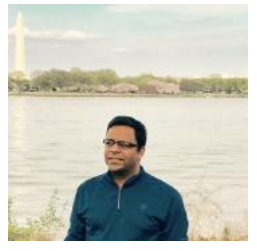

Md Haris Uddin Sharif is a Ph.D. student of Information technology at the University of the Cumberlands. His research interest includes Cyber Security, Cloud Technology, Cloud Security, Application Development, Application Security, Blockchain and Data Security. In addition to these, he engaged in research activities throughout his Ph.D. program and has several research papers (IJCIT, SCI-INT, IJERM, IJEAST, IJMTT, Research Gate, IJEAS and other).

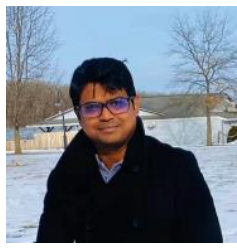

Ripon Datta, Ph.D. candidate at the Department of Information Technology, University of the Cumberlands, Kentucky, United States of America. He is also a Senior Software Engineer in a Financial Corporation in the United States. Mr. Datta's research interest includes Software Development, Blockchain, Machine Learning, Application Security, Algorithm, etc. 